\title{
Quantification of common aminopolycarboxylic acids in trench leachate from the Low Level Waste Repository
}

\author{
James A. O'Hanlon ${ }^{1}$ (D) $\cdot$ Robert D. Chapman ${ }^{1} \cdot$ Frank Taylor $^{2} \cdot$ Melissa A. Denecke $^{1}$
}

Received: 20 May 2019 / Published online: 11 November 2019

(c) The Author(s) 2019

\begin{abstract}
The aminopolycarboxylic acids (APCAs), ethylenediaminetetraacetic acid (EDTA), diethylenetriaminepentaacetic acid (DTPA) and nitrilotriacetic acid (NTA), are used as decontamination agents throughout the nuclear industry; therefore, APCAs are often found in radioactive waste. Limits of acceptance on APCAs are imposed on wastes consigned to the Low Level Waste Repository (LLWR) because, when present in the waste, the ligands have the potential to mobilise otherwise surface-bound or solid radionuclides, making them available for transport to groundwater and ultimately to the bio-sphere. A selective and sensitive methodology to detect and quantify these ligands in a range of complex matrices is advantageous in supporting waste acceptance processes. A reversed-phase high-performance liquid chromatography (HPLC) procedure has been applied for quantification of EDTA, DTPA and NTA in their Fe(III)-complex form. Method validation results show linearity $\left(r^{2}>0.999\right)$, precision (intra/inter-day $\% \mathrm{RSD} \leq 10 \%$ ), accuracy (recovery $=100 \pm 3 \%$ ), sensitivity (minimum limits of detection $=0.31,0.38$ and $4.3 \mu \mathrm{M}$ for EDTA, DTPA and NTA, respectively) and selectivity (simultaneous determination of the three APCA complexes achieved with baseline resolution) for Fe(III)-APCAs in aqueous solution. Chromatographic peak overlap is observed for samples containing Fe(III)- and Co(III)-EDTA; two deconvolution methods (2D least-squares fitting vs. PARAFAC) were applied to resolve the peaks and the performances compared. The optimised HPLC method was applied to trench leachate samples from the LLWR site. EDTA was detected with $0.4 \mu \mathrm{M}<$ concentrations $<1 \mu \mathrm{M}$ in samples from four of the six sampling locations tested. The levels are not considered sufficient to increase the risk of radionuclide mobilisation. The technique is considered to be robust and will be considered further in informing limits of acceptance on APCAs.
\end{abstract}

Keywords High-performance liquid-chromatography $\cdot$ Ion-pair · Aminopolycarboxylic acids $\cdot$ Ethylenediaminetetraacetic acid $\cdot$ PARAFAC $\cdot$ Low level radioactive waste

\section{Introduction}

The Low Level Waste Repository (LLWR, near Drigg, Cumbria) is the United Kingdom's national facility for the disposal of low level radioactive waste (LLW). LLW consigned

Electronic supplementary material The online version of this article (https://doi.org/10.1007/s10967-019-06895-x) contains supplementary material, which is available to authorized users.

James A. O’Hanlon

james.ohanlon@manchester.ac.uk

1 The Chemistry Building, The University of Manchester, Oxford Road, Manchester M13 9PL, UK

2 LLW Repository Ltd, Pelham House, Pelham Drive, Calderbridge, Seascale, Cumbria CA20 1DB, UK to the repository is encapsulated in a cementitious grout within mild steel ISO containers and stacked in engineered vaults. Operations at the site are planned to extend into the early part of the next century [1].

The aminopolycarboxylic acids (APCAs), ethylenediaminetetraacetic acid (EDTA), diethylenetriaminepentaacetic acid (DTPA) and nitrilotriacetic acid (NTA), are used throughout the nuclear industry in decontamination agents used, for example, in decommissioning processes [2-5]. Left untreated, APCAs can be present in repository consigned wastes. These ligands are chelators and can potentially coordinate, solubilise and mobilise otherwise surface adsorbed or solid radionuclides in the waste. This can lead to a negative impact on the environment; upon contact with infiltrating water, radioactive or heavy metal ions complexed and sequestered by APCAs can be transported out 
of the repository, through the near field, and into the geo/ bio-sphere [4-7]. Another related effect of such chelating and mobilisation is potential destabilisation of cementitious wasteforms through coordination and solubilisation of $\mathrm{Ca}^{2+}$ in the cement [8]. For these reasons, the APCAs were part of LLWR's focus in the 2011 Environmental Safety Case (2011 ESC), which is a pre-requisite for the granting of an Environmental Permit to dispose of LLW in the repository [1].

The environmental permit for the LLWR originally prohibited acceptance of wastes containing organic complexants [9]. An application to the Environment Agency was made in 2015 to vary the permit to allow the disposal of organic complexants, alongside other improvements, provided evidence from geochemical modelling that APCAs could be safely disposed in waste under stringent controls [10-12]. Modelling of radionuclide behaviour in the presence of EDTA indicated that a concentration of $1 \mu \mathrm{M}$ in the LLWR trenches and $60 \mu \mathrm{M}$ loading in its vaults does not increase the associated risk of radionuclide mobilisation beyond legal, acceptable limits [11, 13].

To fulfil the constraints outlined by the revised permit and detailed in the current Waste Acceptance Criteria (WAC) [12], a robust methodology to quantify APCAs at trace concentrations to an acceptable degree of certainty is of considerable benefit to demonstrate waste compliance. The method must be capable of quantifying the analytes in a range of matrices; potential matrices include water derived from trench leachate and incoming waste-streams from a range of sources (e.g. ion-exchange resins generated from the operation and maintenance of submarine nuclear reactors [14]).

An additional aspect important for APCA quantification and related to waste acceptance is the fact that the APCAs, distinct from other organic complexants, exhibit varying degrees of environmental persistence. EDTA is known to be highly resistant to biodegradation, especially under anaerobic or reducing conditions, whilst microbial degradation of NTA has been observed $[4,8,11,13,15-18]$. Reports in the literature are less conclusive about the environmental fate of DTPA, but suggest that it will degrade faster than EDTA, but at a slower rate than NTA $[4,16,19]$. Abiotic factors that also impact the rate of APCA degradation include photolytic [20], radiolytic [21] and chemical degradation pathways [22]. The latter are facilitated by a high ionic strength of disposed waste [23] and a high $\mathrm{pH}$ environment caused by the grouting cement [24].

Historically, different methods have been used for APCA determination, e.g. titrimetric, liquid/gas-chromatographic $[16,18,25]$, potentiometric $[16,26]$, capillary electrophoretic [27] and spectrophotometric methods [28]. High-performance liquid-chromatography (HPLC) has been proven to be a reliable method for APCA analysis in complex sample matrices, owing to its high selectivity and sensitivity $[16,18$, 25, 29-31]. Most HPLC methods involve a reversed-phase
(RP) system with UV-detection of APCA as its Fe(III) or $\mathrm{Cu}$ (II) complex [16, 30, 31] (use of other metal ions has been reported, e.g. Ni, $\mathrm{Cr}(\mathrm{III}), \mathrm{Zn}, \mathrm{Co}, \mathrm{Pb}$ [18], Gd(III), $\mathrm{Lu}(\mathrm{III})$ [28]). A range of mobile phases have been successfully applied to elute the complex species (e.g. acidified $\mathrm{Fe}(\mathrm{III})$ chloride solution [29], water-methanol and acetonitrile-phosphate buffer [30]). In 1996 Nowack et al. report a RP-HPLC metal-EDTA quantification method, implementing a formate-formic acid buffer [18]. Upon inclusion of a pre-concentration step, they reported the limit of detection (LOD) to be $3 \mathrm{nM}$ for Fe(III)-EDTA. Nowack's method was designed for EDTA analysis in natural aqueous samples with heterogeneous phases, making it ideal for application to LLWR samples.

We have developed and tested a modification of the Nowack method for simultaneous detection of EDTA, DTPA and NTA in the form of their Fe(III)-complexes. Our results using this method following optimisation are compared with those from the literature [16, 25, 32]. Developments in modern stationary phase technology have seen the rise of monolithic silica columns as a viable alternative to conventional particle-based columns [33]. We have performed comparative test of the method using both types of stationary phase: commercially available monolithic silica (Chromolith) and a conventional $\mathrm{C}_{18}$ column.

The RP-HPLC EDTA quantification method relies on the conversion of unbound-EDTA or complexed-EDTA to $\mathrm{Fe}(\mathrm{III})$-EDTA for detection at a pre-determined wavelength of maximum absorption $(258 \mathrm{~nm})$ and retention time. The ferric ion was used because of its relatively high $\log \beta_{\mathrm{M} \text {-EDTA }}$ stability constant (25 [34]) and environmental ubiquity. However, real sample matrices may contain a range of metal ions with the potential to interfere with the analysis. One example of this is the $\mathrm{Co}$ (III) ion, which has an EDTA stability constant many orders of magnitude higher than that of $\mathrm{Fe}(\mathrm{III})\left(\log \beta_{\mathrm{Co}(\mathrm{III}) \text {-EDTA }}=40\right.$ [34]). Therefore, if the Co(III) ion or Co(III)-EDTA exist in the sample matrix, formation of or conversion to the Fe(III)-EDTA complex species may be thermodynamically unfavourable. In this case, the interfering species must also be quantified to accurately quantify the EDTA present.

The quantification of both Fe(III)-EDTA and Co(III)EDTA is challenging, due to their chemical similarity. Their HPLC retention times using our method are roughly $0.15 \mathrm{~min}$ apart, meaning that the chromatographic peaks are convoluted. The difference in the electronic configuration between the two transition metal centres contribute to distinctive UVabsorption maxima (Fe(III)-EDTA $\lambda_{\max }=258 \mathrm{~nm}, \mathrm{Co}(\mathrm{III})$ EDTA $\lambda_{\max }=228 \mathrm{~nm}$ ). The HPLC-UV detector used is a diode-array detector (DAD), which allows simultaneous data acquisition over a broad spectral range, for the entire chromatographic range, resulting in three-dimensional datasets, such as that plotted in Fig. 1 ( $x=$ retention time, $y=$ intensity 
Fig. $13 \mathrm{D}$ plot showing the experimental chromatographic peaks of a 1:1 mixture of Fe(III)-EDTA and Co(III)EDTA with respect to both retention time and absorption wavelength

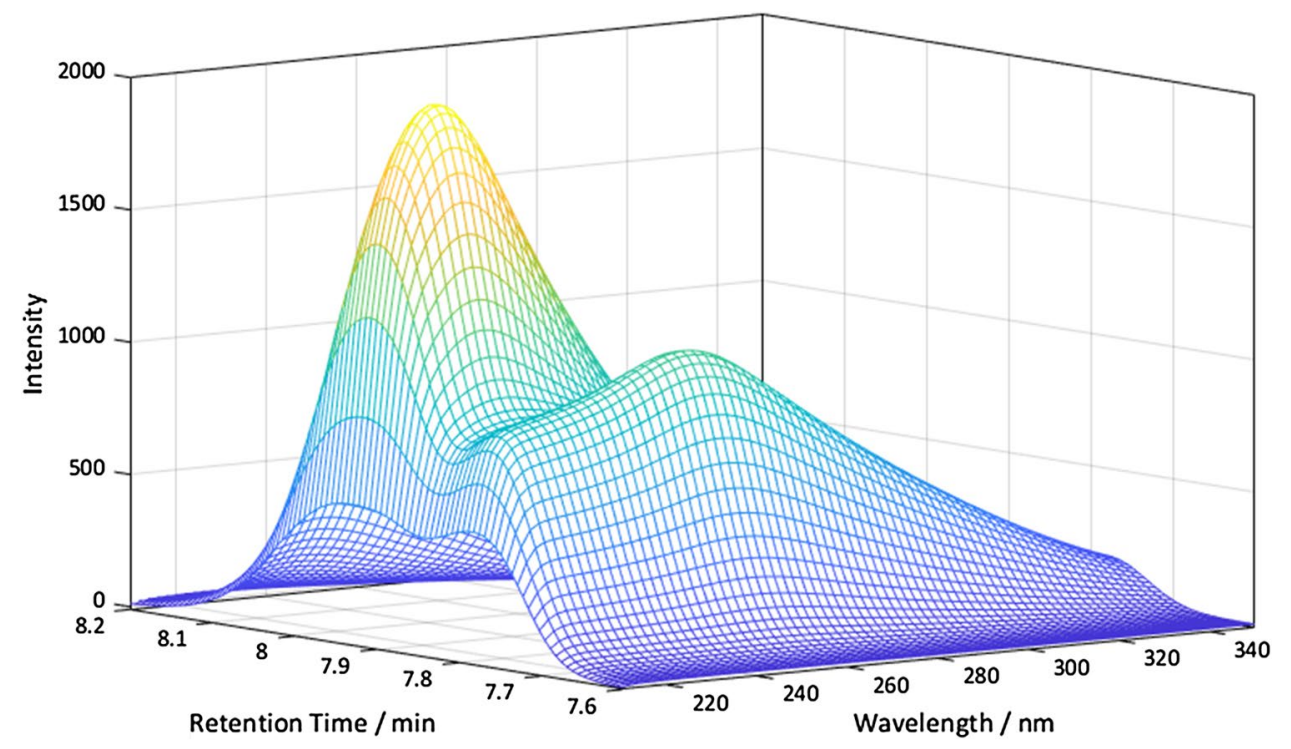

and $z=$ wavelength of absorption). From Fig. 1 it is evident that, although the two M(III)-EDTA have different absorption maxima, both species absorb over the majority of the UV-wavelength range.

To accurately quantify EDTA in Fe(III)-EDTA and Co(III)-EDTA mixtures, HPLC chromatographic peaks must first be deconvoluted, both in terms of retention times and detected absorption. The generous quantity of data afforded by the DAD enables peak deconvolution. Two distinct methods have been explored: a conventional least-squares fitting approach and a newer chemometric technique (Parallel Factor Analysis (PARAFAC)) [35]. PARAFAC is a multi-way decomposition method for high-order datasets. The method originated in psychometric data analysis [36, 37 , but is constantly growing in popularity as a chemometric tool [35]. Application of PARAFAC to HPLC-DAD has been reported previously [38, 39]. We have compared the accuracy and efficiency of each deconvolution method applied to HPLC-DAD data collected for a series of mixtures containing varying concentrations of Fe(III)-EDTA and $\mathrm{Co}$ (III)-EDTA.

Ultimately, the optimised and validated HPLC and deconvolution methods, were applied to a series of trench leachate samples collected from various sampling locations around the LLWR site.

\section{Experimental}

\section{Chemicals and reagents}

EDTA disodium salt $\left(\mathrm{Na}_{2}\right.$ EDTA $\left.\cdot 2 \mathrm{H}_{2} \mathrm{O}\right)$, iron trichloride hexahydrate $\left(\mathrm{FeCl}_{3} \cdot 6 \mathrm{H}_{2} \mathrm{O}\right)$, iron-EDTA monosodium trihydrate $\left(\mathrm{NaEDTA}-\mathrm{Fe}(\mathrm{III}) \cdot 3 \mathrm{H}_{2} \mathrm{O}\right.$ ), DTPA (protonated form), NTA (protonated form), ethanol, tetrabutylammonium bromide (TBA-Br), sodium formate, acetonitrile (HPLC Grade, > 99.9\%) (Sigma-Aldrich, Merck KGaA, Darmstadt, Germany), formic acid, hydrogen peroxide ( $>30 \% \mathrm{~m} / \mathrm{v}$ ) (Fisher Scientific, Loughborough, UK) and cobalt dichloride hexahydrate $\left(\mathrm{CoCl}_{2} \cdot 6 \mathrm{H}_{2} \mathrm{O}\right)$ (MP Biomedicals, Irvine, CA, USA) were obtained at ACS reagent grade or above. Deionised (DI) water $(>18 \mathrm{M} \Omega / \mathrm{cm})$ used for all applications was obtained from a Millipore ${ }^{\circledR}$ system, fitted with a SimPak ${ }^{\circledR} 1$ cartridge (Merck Chemicals Ltd, Nottingham, UK).

\section{Chromatography}

\section{Chromatographic equipment}

HPLC analysis was performed on an Agilent 1260A system (Agilent Technologies, Santa Clara, CA, USA) coupled to a diode-array detector (DAD). The DAD was programmed to record UV-absorption (190-400 nm) over the entire chromatographic retention time range. The system was fitted with a quaternary pump, online degasser, autosampler with $100 \mu \mathrm{L}$ sample loop and thermostatted column oven. The monolithic silica column was a Chromolith ${ }^{\circledR}$ HighResolution RP-18 end-capped $(4.6 \times 150 \mathrm{~mm})$ analytical column fitted with a Chromolith ${ }^{\circledR}$ HighResolution monolithic silica RP-18 end-capped $(4.6 \times 5 \mathrm{~mm})$ guard cartridge (Merck Millipore, Merck Chemicals Ltd, Nottingham, UK). The particle-based column was a Phenomenex ${ }^{\circledR}$ HyperClone $5 \mu \mathrm{M}$ BDS $\mathrm{C}_{18}(4.6 \times 250 \mathrm{~mm})$ fitted with SecurityGuard ${ }^{\circledR} \mathrm{C}_{18}$ guard cartridge $(4.6 \times 5 \mathrm{~mm})$ (Phenomenex Ltd, Macclesfield, UK). 


\section{Chromatographic conditions}

All chromatography was carried out isocratically at $25{ }^{\circ} \mathrm{C}$ with a $0.6 \mathrm{~mL} / \mathrm{min}$ flow-rate of buffered mobile phase (20 mM formate buffer, $\mathrm{pH} 3.3$, prepared by dissolving $10 \mathrm{mM}$ TBA-Br ion-pair agent, $5 \mathrm{mM}$ sodium formate, $15 \mathrm{mM}$ formic acid, and $8 \%$ acetonitrile in DI water), with two exceptions: 1) elution of Fe(III)-DTPA was performed using a 90:10 ratio of formate buffer:acetonitrile, to raise the total composition of acetonitrile to $17.2 \%$, and 2) separation of solutions containing three Fe(III)-APCA complexes was achieved using a gradient elution ( $0-10 \mathrm{~min}$, a gradient flow of formate buffer:acetonitrile ran from 100:0 to 90:10; $10-20 \mathrm{~min}$, the system pumped isocratically at the final ratio (90:10)). The injection volume was $10 \mu \mathrm{L}$ and always performed in duplicate. Elution was monitored at the respective $\lambda_{\max }$ of either M(III)-APCA complex (258 nm and $228 \mathrm{~nm}$ ).

\section{Preparation of samples for method validation}

\section{Synthesis of Co(III)-EDTA}

Equimolar quantities of $\mathrm{CoCl}_{2} \cdot 6 \mathrm{H}_{2} \mathrm{O}$ and $\mathrm{Na}_{2}$ EDTA $2 \mathrm{H}_{2} \mathrm{O}$ were dissolved in a minimal amount of mildly basic aqueous solution. The solution was heated under reflux for $24 \mathrm{~h}$, over which period three $2 \mathrm{~mL}$ aliquots of $\mathrm{H}_{2} \mathrm{O}_{2}$ solution were added at evenly spaced intervals. Crystallisation was allowed to occur during evaporation. The resulting precipitate was collected by vacuum filtration and washed with cold ethanol. Recrystallization from a mixture of water and ethanol yielded deep-purple, needle-like crystals, which were collected by vacuum filtration, washed with cold ethanol and dried in a vacuum desiccator. The Co(III)-EDTA complex was characterised by MS, UV-Vis, P-XRD, TGA, ICPMS and HPLC. The structure was found to be NaEDTA$\mathrm{Co}(\mathrm{III}) \cdot 2 \mathrm{H}_{2} \mathrm{O}$. Single crystal XRD analysis of the Co(III)EDTA product was prohibited by the fine needle crystal morphology.

\section{Calibration samples}

$\mathrm{Fe}(\mathrm{III})$-EDTA/DTPA/NTA stock solutions were each prepared by dissolving $\mathrm{Na}_{2}$ EDTA $2 \mathrm{H}_{2} \mathrm{O}(0.3722 \mathrm{~g}, 1 \mathrm{mmol})$, DTPA $(0.3935 \mathrm{~g}, 1 \mathrm{mmol})$ or NTA $(0.1911 \mathrm{~g}, 1 \mathrm{mmol})$ in DI water $(70 \mathrm{~mL})$. Solutions of $\mathrm{Fe}$ (III) were prepared by dissolving $0.2750 \mathrm{~g}$ (0.02 molar excess over APCAs) of $\mathrm{FeCl}_{3} \cdot 6 \mathrm{H}_{2} \mathrm{O}$ in DI water $(10 \mathrm{~mL})$ and added to the APCA solutions. Solutions were heated to $100{ }^{\circ} \mathrm{C}$ under stirring $(1 \mathrm{~h})$, thermally equilibrated $(3 \mathrm{~h})$, added to a volumetric flask $(100 \mathrm{~mL})$, and then made up to $100 \mathrm{~mL}(10 \mathrm{mM})$. Another stock solution of $\mathrm{Fe}(\mathrm{III})$-EDTA was prepared by dissolving NaEDTA-Fe(III) $3 \mathrm{H}_{2} \mathrm{O}(0.8484 \mathrm{~g}, 2 \mathrm{mmol})$ in DI water $(95 \mathrm{~mL})$ in a $100 \mathrm{~mL}$ volumetric flask, swirled until dissolved, thermally equilibrated $(3 \mathrm{~h})$ and then made up to $100 \mathrm{~mL}$ (20 mM). A stock solution of Co(III)-EDTA was prepared from the synthesised product by the same method $(0.8120 \mathrm{~g}, 100 \mathrm{~mL}, 20 \mathrm{mM})$. Stock solutions were diluted in triplicate to yield $1000,100,10,1$ and $0.1 \mu \mathrm{M}$ solutions and transferred to $2 \mathrm{~mL}$ autosampler vials for analysis. When not in use, all samples and stock solutions were refrigerated at $4{ }^{\circ} \mathrm{C}$ and kept under darkness to limit thermal/ photo-degradation.

\section{$\mathrm{Co} / \mathrm{Fe}(\mathrm{III})-\mathrm{EDTA}$ mixtures}

The $20 \mathrm{mM}$ stock solutions of Fe(III)-EDTA and Co(III)EDTA (prepared from crystalline samples) were diluted in triplicate to 2000, 200, 160, 120, 80, 40, 20, 2 and $0.2 \mu \mathrm{M}$. Samples of $\mathrm{Fe}$ (III)/Co(III)-EDTA mixtures were made by combining $0.5 \mathrm{~mL}$ aliquots of stock solution in $2 \mathrm{~mL}$ autosampler vials, yielding 25 distinct sample mixtures, each with nine replicates.

\section{Preparation of trench leachate samples}

All heterogeneous leachate samples taken from various sampling locations around the LLWR site (designated GD6, GD7, GD8, GD10, GD12 and GD13) were filtered by vacuum filtration (Whatman ${ }^{\circledR}$ Grade $190 \mathrm{~mm}$ filter paper) prior to analysis. Three of the leachate samples were spiked with known amounts of EDTA at three concentration levels. All filtered solutions were also analysed with the HPLC method in their original, un-spiked form. All analyte solutions were prepared in triplicate.

To prepare the EDTA-spiked samples, an EDTA stock solution $(7.82 \mathrm{mM})$ was prepared by dissolving $\mathrm{Na}_{2}$ EDTA $2 \mathrm{H}_{2} \mathrm{O}$ in DI water $(0.2911 \mathrm{~g}, 0.782 \mathrm{mmol}$, $100 \mathrm{~mL}$ ) and diluted to 782 and $78.2 \mu \mathrm{M}$. Nine $9 \mathrm{~mL}$ aliquots of liquid-phase from GD10, GD11 and GD12 were transferred to $14 \mathrm{~mL}$ screwcap glass vials. $1 \mathrm{~mL}$ of the EDTA stock solutions (7820, 782 and $78.2 \mu \mathrm{M})$ was added to the $9 \mathrm{~mL}$ aliquots of trench leachate, to make three concentrations of EDTA-spiked samples (782 $\mu \mathrm{M}, 78.2 \mu \mathrm{M}$ and $7.82 \mu \mathrm{M}$ spikes). Aliquots of the spiked samples were transferred to $2 \mathrm{~mL}$ autosampler vials and analysed by HPLC. Both the spiked and un-spiked samples were heated $\left(65^{\circ} \mathrm{C}\right.$, $12 \mathrm{~h}$ ) in the capped glass vials in a sand bath and, after cooling, analysed by the same HPLC method.

\section{Peak deconvolution and data processing}

HPLC data of single species chromatograms was initially processed using Agilent's ChemStation OpenLAB software (V. A.01.02). Chromatograms recorded for $\mathrm{Fe}(\mathrm{III}) / \mathrm{Co}$ (III)EDTA mixtures and trench leach samples underwent further processing to deconvolute the overlapping peaks. 


\section{Least-squares fitting}

An average two-dimensional array was calculated from the HPLC-DAD data recorded for each calibration solution and $\mathrm{Fe}(\mathrm{III}) / \mathrm{Co}$ (III)-EDTA mixtures replicates prior to their input into the least-squares fitting (LSF) procedure. A value for $\%$ RSD (percent relative standard deviation) was calculated from the mean and standard deviation of the absorption intensity at the wavelength and retention time of maximum absorption of each raw chromatogram. Chromatograms were accepted into the final dataset if they met the acceptance criteria $(\% \mathrm{RSD} \leq 10 \%)$. Two single-wavelength chromatograms were extracted from the averaged, multi-wavelength data for each sample at $258 \mathrm{~nm}$ and $228 \mathrm{~nm}$. Chromatograms of the calibration samples were fit first to determine the peak shape and fitting parameters. The fitting parameters obtained during analysis of the calibration data were used to guide the initial parameter input during the analysis of the convoluted data obtained from the sample mixtures.

The baseline of each chromatographic peak was determined as a straight line connecting the respective absorption minima $\left(\mathrm{d}^{2} y / \mathrm{d} x^{2}=0\right)$ at retention times before and after the peak elution. The line connecting these points was then rescaled to $y=0$. A Gram-Charlier A Series (GCAS), which is a modified Gaussian curve and used widely for gas chromatographic data [40, 41], was found to best fit the calibration data. The peak position and shape are determined by five fitting parameters: centre, amplitude, half-width and two expansion factors defining the asymmetry of the peak and used to capture the effect of chromatographic peak tailing. Characteristic values of the expansion factors were determined from all calibration chromatograms; these values were inputted and held constant during the analysis of the sample mixture chromatograms, not doing so usually resulted in unrealistic peak shapes. All peak fitting operations and peak area calculations were carried out using OriginPro 2017.
PARAFAC

The PARAFAC method is one of the main deconvolution methods for multi-way data. PARAFAC is an extension to PCA and can automatically determine factors and components from high-order dataset.

The two-dimensional data arrays obtained from the HPLC-DAD were collated into a three-dimensional data array (Fig. 2) and PARAFAC was then used to decompose this array. The 3D matrix $(I \times J \times K)$ is separated into three loadings matrices in Modes 1, 2 and 3, which can then be recombined to produce new $3 \mathrm{D}$ matrices unique to each component and containing information regarding each component's contribution in each dimension. The PARAFAC software in MATLAB requires at least two 2D arrays of the same dimensions and each individual dataset must show a change in contribution to the model; the variable $\mathrm{K}$ must involve a change that affects the magnitude of I and J. In this case, I and J describe the UV-absorption intensities over the chromatographic range, and $\mathrm{K}$ varies according to the concentration of each component.

PARAFAC deconvolution operations and peak integration were carried out on MATLAB R2018a [35]. The PARAFAC code can be found in the $\mathrm{N}$-way Toolbox. CORCONDIA diagnostic evaluates the core consistency of a given PARAFAC model. It was found that the best values for CORCONDIA were obtained by creating two separate datasets; the first containing the results of the samples containing 1000,100 and $10 \mu \mathrm{M}$ concentrations of each complex and another containing the data from the $80,60,40,20 \mu \mathrm{M}$ samples. This is likely due to the fact that the samples were run on different dates, without identical operating conditions, resulting in small differences in peak shape and retention time. The results of the CORCONDIA diagnostic were 99.98 (12 iterations) and 99.99 (18 iterations) for the first and second dataset, respectively.

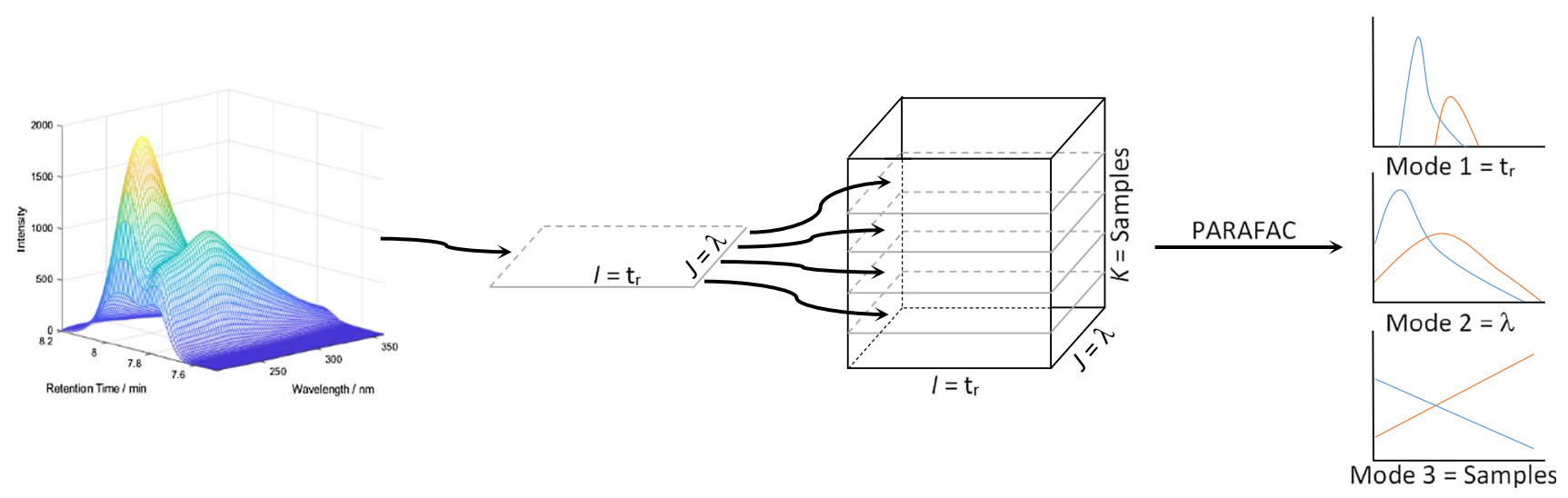

Fig. 2 Schematic of PARAFAC methodology applied to HPLC-DAD data containing two principle components 
After the contribution of each component in each dimension was determined, single-wavelength chromatograms of each complex at their respective $\lambda_{\max }$ were extracted and peak areas calculated using the trapz() integration function.

\section{Trench Leachate Samples}

All chromatograms recorded for trench leachate samples were exported into OriginPro 2017 to undergo the LSF procedure to determine the Fe(III)-EDTA peak area at $258 \mathrm{~nm}$.

\section{Method validation}

\section{Calibration}

The linearity was assessed by calculating the linear regression $\left(r^{2}\right)$ of each calibration curve (mean integrated peak vs. [M(III)-APCA]) (acceptance criteria: $r^{2} \geq 0.98$ ). LODs and values for the limit of quantification (LOQs) were calculated as $3.3(\sigma / S)$ and $10(\sigma / S)$, respectively, where $S$ is the slope and $\sigma$ is the standard deviation of the peak intensities for samples of lowest, measurable concentration. The calculated LOD/LOQ for Fe(III)-EDTA was verified using the Miller and Miller method, where $\sigma$ is the mean intensity plus the standard deviation of the blank [42].

The intra-day precision has been expressed as \% RSD, calculated from the standard deviation of the mean peak area for each data point (acceptance criteria: $\% \mathrm{RSD} \leq 10 \%$ ). The inter-day precision was assessed using Fe(III)-EDTA as a model system; a value for \%RSD was calculated from data recorded for equivalent samples but on different days (when the column was new and after it had been in frequent use for nine months) (acceptance criteria: \% RSD $\leq 10 \%$ ). $\mathrm{Fe}(\mathrm{III})$-EDTA made by forming the complex in solution was also used to assess the accuracy of the method by expressing mean peak areas recorded for these solutions as percent recovery of the equivalent data for the stock solution made by dissolving the crystalline complex (acceptance criteria: recovery $=100 \pm 10 \%$ ).

Additionally calibration data was assessed for $r^{2}$, LOD/ LOD, $S$ and \%RSD (intra-day) when analysed using the two peak deconvolution methods, LSF and PARAFAC, discussed in the next section.

\section{Peak deconvolution}

The accuracy of each peak deconvolution method was assessed by plotting the deconvoluted peak area obtained for mixtures of $\mathrm{Fe}$ (III)- and $\mathrm{Co}$ (III)-EDTA using either the LSF or PARAFAC method, expressed as a percentage of the expected value (known concentrations). A linear regression of such a plot should ideally give the equation $y=100 \%$. The extent to which the linear regression of each real dataset diverges from this ideal value gives a measure of the accuracy and suggests potential trends in the systematic error.

The error associated with the peak areas recorded for $\mathrm{Fe}(\mathrm{III}) / \mathrm{Co}$ (III)-EDTA mixtures represent the statistical error from the LSF procedure, which is the vector sum of the statistical error associated with the three variable fitting parameters used to define each GCAS curve (position of centre, half-width and amplitude). The error associated with the results of the PARAFAC method represent one standard deviation calculated from the integrated peak areas recorded for each chromatogram at each concentration.

\section{Trench leachate samples}

Three samples of trench leachate were spiked with EDTA disodium salt at three concentration levels to assess the recovery and behaviour of the ligand in a real sample matrix. No Fe(III)-salt was added; it was expected that sufficient concentrations of $\mathrm{Fe}(\mathrm{III})$ would naturally be present in the environmental matrix to 1:1 complex trace concentrations of EDTA. This was also designed to allow insight into the speciation behaviour of the ligand under the real sample conditions.

The percent recovery of EDTA as Fe(III)-EDTA was defined as the peak areas recorded for the EDTA-spiked samples normalised to the expected areas calculated from calibration data obtained for Fe(III)-EDTA in purely aqueous conditions, multiplied by 100 . The percent recovery was used to estimate the amounts of free EDTA and Fe(III)EDTA complex, when the ligand is present at varying concentrations in a real sample matrix. Extrapolation of the linear trend of a logarithmic plot of [Fe(III)-EDTA (detected)] versus percent recovery of EDTA as Fe(III)-EDTA from the spiked samples was used to estimate the total concentration of EDTA present in un-spiked trench leachate samples by an inverse operation of the concentration detectable as $\mathrm{Fe}(\mathrm{III})-\mathrm{EDTA}$.

\section{Results and discussion}

\section{Calibration}

The determined metrics describing sensitivity and linearity of the HPLC method, applied to three types of M(III)APCA complexes and using the monolithic silica column, are displayed in Table 1. Equivalent results obtained using a different column (conventional particle-based $\mathrm{C}_{18}$ ) and a greater injection volume $(100 \mu \mathrm{L})$ can be found in the SI. The monolithic stationary phase was found to afford greater chromatographic precision and sensitivity than the $C_{18}$ 
Table 1 LOD, LOQ, slope, linearity and \%RSD values for the M(III)-APCA complexes under the chromatographic conditions

\begin{tabular}{llllll}
\hline M(III)-APCA & LOD/ $\mu \mathrm{M}$ & LOQ/ $\mu \mathrm{M}$ & $\begin{array}{l}\text { Slope/ } \\
\mathrm{mAU} \\
\mu \mathrm{mol}^{-1} \mathrm{~L}\end{array}$ & $R^{2}$ & $\% \mathrm{RSD}$ \\
\hline Co(III)-EDTA* & 0.13 & 0.38 & 17.02 & 0.9999 & 3.8 \\
Fe(III)-EDTA* & 0.37 & 1.1 & 9.255 & 0.9999 & 3.4 \\
Fe(III)-EDTA & 0.31 & 0.94 & 9.298 & 0.9999 & 3.0 \\
Fe(III)-DTPA & 0.38 & 1.1 & 9.084 & 0.9999 & 1.8 \\
Fe(III)-NTA & 4.3 & 13 & 5.563 & 0.9999 & 4.1 \\
\hline
\end{tabular}

M(III)-APCA* = crystalline complex used to make stock solution. $\%$ RSD reported for $10 \mu \mathrm{M}$ calibration standards

column. Unless stated otherwise, the results presented in this paper were obtained from the monolithic silica column.

All reported values of $r^{2}$ for the linear regression of the calibration curves fulfil the acceptance criteria $\left(r^{2} \geq 0.98\right)$. The method is highly sensitive for the EDTA and DTPA complexes tested (LOD range $=0.13-0.38 \mu \mathrm{M}$ ) but less sensitive for $\mathrm{Fe}(\mathrm{III})-\mathrm{NTA}(\mathrm{LOD}=4.3 \mu \mathrm{M})$. This is due to the lower molar extinction coefficient $\left(\varepsilon_{\mathrm{i}}\right)$ for the Fe(III)-NTA complex compared to those for M(III)-EDTA/DTPA, for example, $\varepsilon_{\mathrm{Fe}(\mathrm{III})-\mathrm{NTA}}=5.6 \mathrm{mAU} \mu \mathrm{mol}^{-1} \mathrm{~L}$ and $\varepsilon_{\mathrm{Fe}(\mathrm{III}) \text {-EDTA }}$ $=9.3 \mathrm{mAU} \mu \mathrm{mol}^{-1} \mathrm{~L}$; values for $\varepsilon_{\mathrm{i}}$ derived from the slope of the linear calibration curves. Additionally, the Fe(III)NTA chromatographic peak exhibited poorer resolution versus that of M(III)-EDTA/DTPA. Both the effect of peak asymmetry and low $\varepsilon_{\mathrm{Fe}(\mathrm{III}) \mathrm{NTA}}$ are best visualised in Fig. 3, where the chromatogram of a mixture of $\mathrm{Fe}(\mathrm{III})$-complexes of EDTA, DTPA and NTA at equal concentrations is displayed. Despite being present in equal quantities, the $\mathrm{Fe}(\mathrm{III})-\mathrm{NTA}$ peak $\left(\mathrm{t}_{\mathrm{r}}=5.13\right.$ min, Peak 1$)$ is of smaller area and exhibits much greater peak tailing, with a significant shoulder on the high $t_{r}$ flank. The results for Fe(III)-EDTA and DTPA are similar to others reported in the literature; in 2005, Laine et al. reported LODs of 0.27, 0.34 and 0.62 in the simultaneous chromatographic detection of EDTA, DTPA and NTA, respectively [16].

Table 2 shows the accuracy and intra/inter-day precision of the method applied to Fe(III)-EDTA. At all concentrations tested, the accuracy (percent recovery) and precision fall within the acceptance criteria (recovery $=100 \pm 10 \%$, $\% \mathrm{RSD} \leq 10 \%$ ).

A solution containing all three APCA-complexes can be separated to baseline resolution (Fig. 3) by implementing a gradient elution ("Chromatographic Conditions" section). The gradient elution increases the retention time of Fe(III)-DTPA by a factor of roughly 1.5 compared with the isocratic elution of single-species Fe(III)-DTPA samples $\left(\mathrm{t}_{\mathrm{r}} \approx 9 \min <\mathrm{t}_{\mathrm{r}} \approx 14 \mathrm{~min}\right)$. It was found that implementation of a gradient elution was necessary to simultaneously maintain the sharpness of each peak.

The identity of the complex responsible for each peak was confirmed by comparison of the retention times and UV-absorption profiles obtained from the analysis of the mixture to equivalent data recorded for single-species calibration samples. Fe(III)-DTPA (Fig. 3, Peak 3) has the longest of the three retention times $\left(t_{r}=14.14 \mathrm{~min}\right)$, and requires a mobile phase with a greater acetonitrile composition than $\mathrm{Fe}(\mathrm{III})-\mathrm{NTA} / \mathrm{EDTA}$ to maintain the sharpness of the peak. No improvement to the symmetry of the Fe(III)-NTA peak

Table 2 Accuracy and intra/inter-day precision of the HPLC method applied to $\mathrm{Fe}$ (III)-EDTA over a range of concentrations

\begin{tabular}{lrll}
\hline$[\mathrm{Fe}(\mathrm{III})-$ & Accuracy/\% & $\begin{array}{l}\text { Intra-day } \\
\text { precision/\%RSD }\end{array}$ & $\begin{array}{l}\text { Inter-day } \\
\text { precision/\%RSD }\end{array}$ \\
\hline 1000 & 100 & 0.22 & 0.52 \\
100 & 99 & 0.99 & 0.81 \\
10 & 99 & 3.0 & 2.8 \\
1 & 96 & 9.9 & 7.8 \\
\hline
\end{tabular}

See text for details

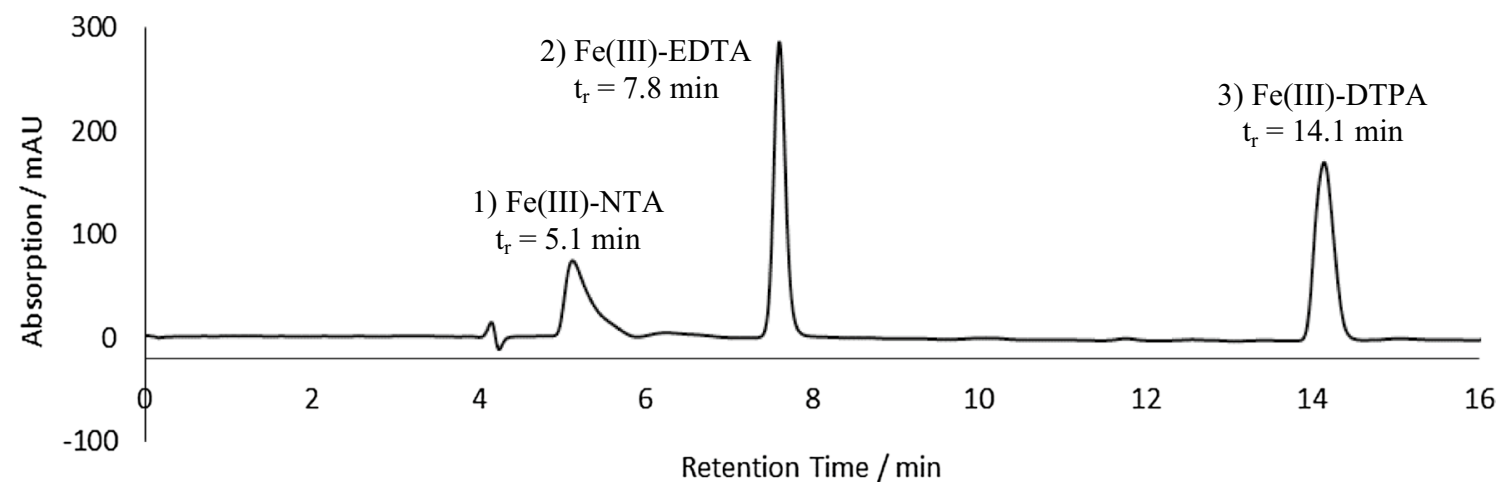

Fig. 3 Chromatogram recorded for an aqueous solution containing three $300 \mu \mathrm{M}$ Fe(III)-APCA complexes (EDTA, DTPA and NTA), absorption at $258 \mathrm{~nm}$ 
was observed throughout the graduated mobile phase screening process; shifting the peak to a lower $t_{r}$ with an increased mobile phase acetonitrile concentration led to overlap with the solvent front.

Although it was possible to separate mixtures containing various Fe(III)-APCA complexes, chromatographic peaks recorded for samples containing mixtures of $\mathrm{Fe}(\mathrm{III})-$ and Co(III)-EDTA were convoluted with respect to both retention time and UV-absorption.

\section{Peak deconvolution}

Two distinct peak deconvolution methods have been explored, LSF and PARAFAC. The results of the analysis of the single-species calibration data by each method are presented in Table 3.

Both methods of peak analysis produce $R^{2}$ values above the acceptance criteria $\left(r^{2} \geq 0.98\right)$. The values of $\%$ RSD at most concentrations indicate good precision $(\% \mathrm{RSD} \geq 10 \%)$; however, high \% RSD values were recorded for low concentration samples analysed by PARAFAC $(1 \mu \mathrm{M} \mathrm{Fe} / \mathrm{Co}(\mathrm{III})-$ $\mathrm{EDTA}=69 / 86 \%$ ). The respective chromatographic peaks at these low concentrations are still clearly separable from background noise. Analysis using LSF of the identical dataset delivers reasonably precise results $(1 \mu \mathrm{M} \mathrm{Fe} / \mathrm{Co}$ (III)EDTA $=10.8 / 3.97 \%)$. The difference may lie in the misalignment of the peak maxima (i.e. slight shifts in retention times with slight variations in chromatographic conditions), which can impact the quality of the PARAFAC model, whereas this can easily be accounted for when fitting the peaks in two-dimensions.

The LOD for Fe(III)- and Co(III)-EDTA obtained by LSF ( 0.35 and $0.13 \mu \mathrm{M}$, respectively) is comparable to the values obtained by integration using Agilent's ChemStation software. The LOD for Co(III)-EDTA is lower, which likely reflects the nearly two-fold larger molar extinction coefficient of the Co(III)-complex at its wavelength of maximum absorption (also reflected in the calibration curve slopes: $\mathrm{Fe} /$ Co(III)-EDTA slope $=0.15 / 0.29)$. The LOD values obtained by PARAFAC are an order of magnitude higher, which results from the greater variance associated with the lowest measurable peak.

LSF and PARAFAC were each used to analyse a sample series of varying $\mathrm{Fe}(\mathrm{III})$ - and $\mathrm{Co}(\mathrm{III})$-EDTA concentrations, made by combining aliquots of single-species stock solutions. The accuracy of each method has been assessed by comparison of the deconvoluted peak area with that of expected values, expressed as percent. The results are shown in Fig. 4; each data point represents 18 chromatograms.

The \%M(III)-EDTA in Fig. 4a, b mostly fall within a range of $100 \pm 10 \%$, showing reasonably good accuracy for both methods. All peaks were quantifiable, except the low intensity peak recorded for samples containing a concentration difference of two orders of magnitude $(1000 \mu \mathrm{M} / 10 \mu \mathrm{M})$. Despite the $10 \mu \mathrm{M}$ concentration generally being above the LOQ, accurate quantification is precluded by interference from the high intensity peak.

Systematic error can be identified by linear regression analysis of the data in Fig. 4; the extent to which each trend deviates from $y=100$ provides two terms ( $m$ and $c$ ) that can be used to measure the error and the trend that it follows (Table 4). For example, Fig. 4a shows the results of the LSF analysis; both slopes $(m)$ are negative, suggesting that there is a systematic overestimation of each species when they are present in low concentrations. This effect is more pronounced for $\mathrm{Fe}$ (III)-EDTA than for Co(III)-EDTA (i.e. steeper negative gradient and larger $y$-intercept). This observation is in agreement with the calculated average value of determined/expected concentrations in percent ( $\mathrm{Fe}(\mathrm{III}) /$ $\mathrm{Co}(\mathrm{III})$-EDTA $=102.6 \pm 4.2 / 100.2 \pm 4.3 \%$ ).

Figure $4 \mathrm{~b}$ shows the PARAFAC results; a positive slope and $x$-intercept $<100$ was determined for Fe(III)-EDTA and a negative slope and $x$-intercept $>100$ for Co(III)-EDTA (Table 4). This result suggests the analysis yields an overestimation of $\mathrm{Fe}(\mathrm{III})$-EDTA at high concentrations, but tends towards a systematic underestimation with decreasing concentration. The concentration of Co(III)-EDTA appears to be consistently overestimated. These observations are also in line with the average measurement accuracies ( $\mathrm{Fe}(\mathrm{III}) /$ Co(III)-EDTA $=98.4 \pm 6.3 / 106.6 \pm 5.6 \%$ ).

The values of random error associated with each measurement are generally greater for Fe(III)-EDTA than Co(III)-EDTA and exhibit more variation in the results of both deconvolution methods (LSF mean standard error of $\mathrm{Fe}(\mathrm{III}) / \mathrm{Co}$ (III) $-\mathrm{EDTA}=4.5 \pm 3.7 / 1.5 \pm 0.7 \%$, PARAFAC mean \%RSD of $\mathrm{Fe}(\mathrm{III}) / \mathrm{Co}(\mathrm{III})$ $\mathrm{EDTA}=9.8 \pm 8.9 / 3.6 \pm 3.4 \%)$. Furthermore, in both cases the error associated with $\mathrm{Fe}$ (III)-EDTA measurements

Table 3 LOD, LOQ, slope, linearity and \%RSD Fe(III)-EDTA and Co(III)-EDTA, recorded at their respective wavelengths of maximum absorption, obtained by application of comparative data analysis techniques

\begin{tabular}{|c|c|c|c|c|c|c|c|c|c|c|}
\hline & \multicolumn{5}{|c|}{ Least-squares fitting } & \multicolumn{5}{|c|}{ PARAFAC } \\
\hline & $\mathrm{LOD} / \mu \mathrm{M}$ & $\mathrm{LOQ} / \mu \mathrm{M}$ & Slope & $R^{2}$ & $\% \mathrm{RSD}$ & $\mathrm{LOD} / \mu \mathrm{M}$ & $\mathrm{LOQ} / \mu \mathrm{M}$ & Slope & $R^{2}$ & $\% \mathrm{RSD}$ \\
\hline Fe(III)-EDTA & 0.35 & 1.1 & 0.15 & 0.9999 & 5.08 & 2.3 & 7.1 & 0.10 & 0.9999 & 14.2 \\
\hline Co(III)-EDTA & 0.13 & 0.39 & 0.29 & 0.9999 & 0.81 & 4.4 & 13 & 0.15 & 0.9999 & 14.0 \\
\hline
\end{tabular}


tends to increase with decreasing concentration of the complex in the sample mixture, whereas the magnitude of the error associated with Co(III)-EDTA generally remains consistent over the studied range.
The graphs in Fig. 5 visualise the effect that the UVabsorption characteristics of the two complexes have on peak resolution. Because of the greater molar extinction coefficient for Co(III)-EDTA at its maximum absorption,
Fig. 4 a The percent concentration determined from least-squares fitting, relative to expected concentrations, plotted against the Fe(III)-EDTA and Co(III)-EDTA concentrations in each sample mixture (error bars $=$ standard error). $\mathbf{b}$ The percent concentration determined from PARAFAC, relative to expected concentrations, plotted against the $\mathrm{Fe}$ (III)-EDTA and $\mathrm{Co}$ (III)-EDTA concentrations in each sample mixture (error bars $=\% \mathrm{RSD})$. Horizontal dotted lines $(y=100 \pm 10)$ denote confidence interval $(100 \pm 10 \%)$. Inserts: Expansion of the low concentration region of the graphs

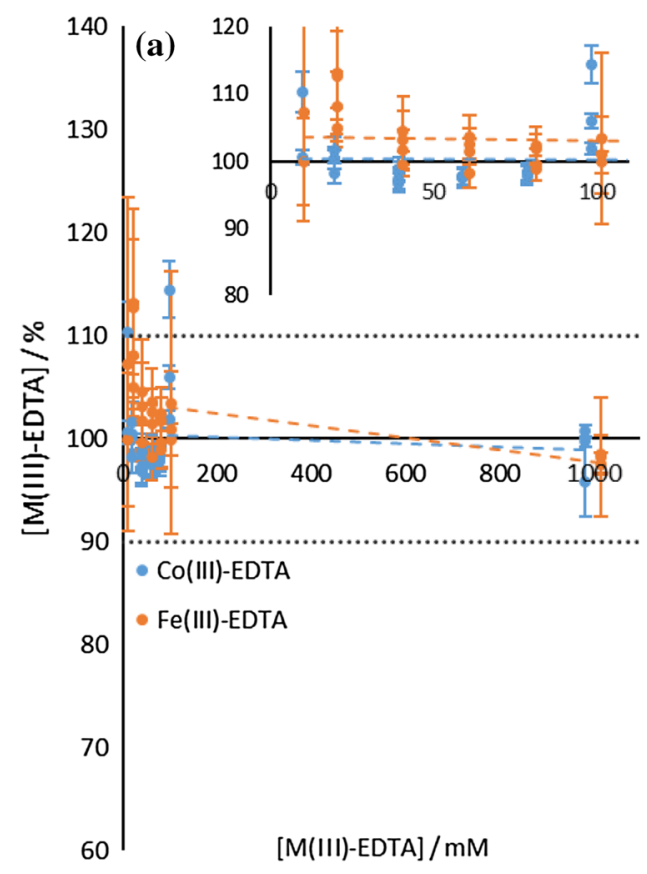

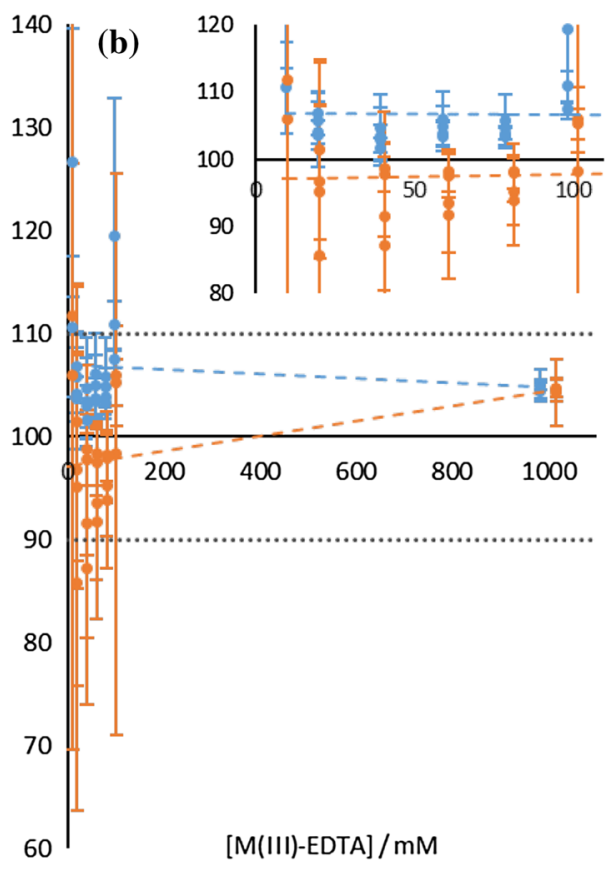

Table 4 Parameters of linear equations derived from the linear regression of plots of deconvolution results from the least-squares fitting or PARAFAC method. $m=$ gradient and $c=y$-intercept

\begin{tabular}{lllllrrr}
\hline & \multicolumn{2}{l}{ Least-squares fitting } & & & \multicolumn{2}{l}{ PARAFAC } \\
\cline { 2 - 4 } \cline { 5 - 7 } & $M$ & $C$ & $R^{2}$ & & \multicolumn{2}{c}{$C$} & $R^{2}$ \\
\hline Fe(III)-EDTA & -0.0059 & 103.6 & 0.2073 & 0.0073 & 97.12 & 0.1432 \\
Co(III)-EDTA & -0.0016 & 100.45 & 0.0136 & -0.0022 & 106.98 & 0.0159 \\
\hline
\end{tabular}

Fig. 5 Graphical view of fitted chromatographic data of sample mixtures in the 80-20 $\mu \mathrm{M}$ range. Orange dashes $=\mathrm{Fe}(\mathrm{III})-$ EDTA fit results,

blue $=\mathrm{Co}(\mathrm{III})-$ EDTA fit results, black dashes $=$ overall fit, and black lines $=$ experimental data. a $[\mathrm{Co}$ (III)-EDTA $]=80 \mu \mathrm{M}$, varying $[\mathrm{Fe}(\mathrm{III})-\mathrm{EDTA}]=20$, $40,60,80 \mu \mathrm{M}$ (recorded at $\left.258 \mathrm{~nm}=\mathrm{Fe}(\mathrm{III})-\mathrm{EDTA} \lambda_{\max }\right)$, b $[\mathrm{Fe}(\mathrm{III})-\mathrm{EDTA}]=80 \mu \mathrm{M}$, varying $[\mathrm{Co}(\mathrm{III})-\mathrm{EDTA}]=20$, $40,60,80 \mu \mathrm{M}$ (recorded at $228 \mathrm{~nm}=\mathrm{Co}(\mathrm{III})-$ EDTA $\left.\lambda_{\max }\right)$. (Color figure online)
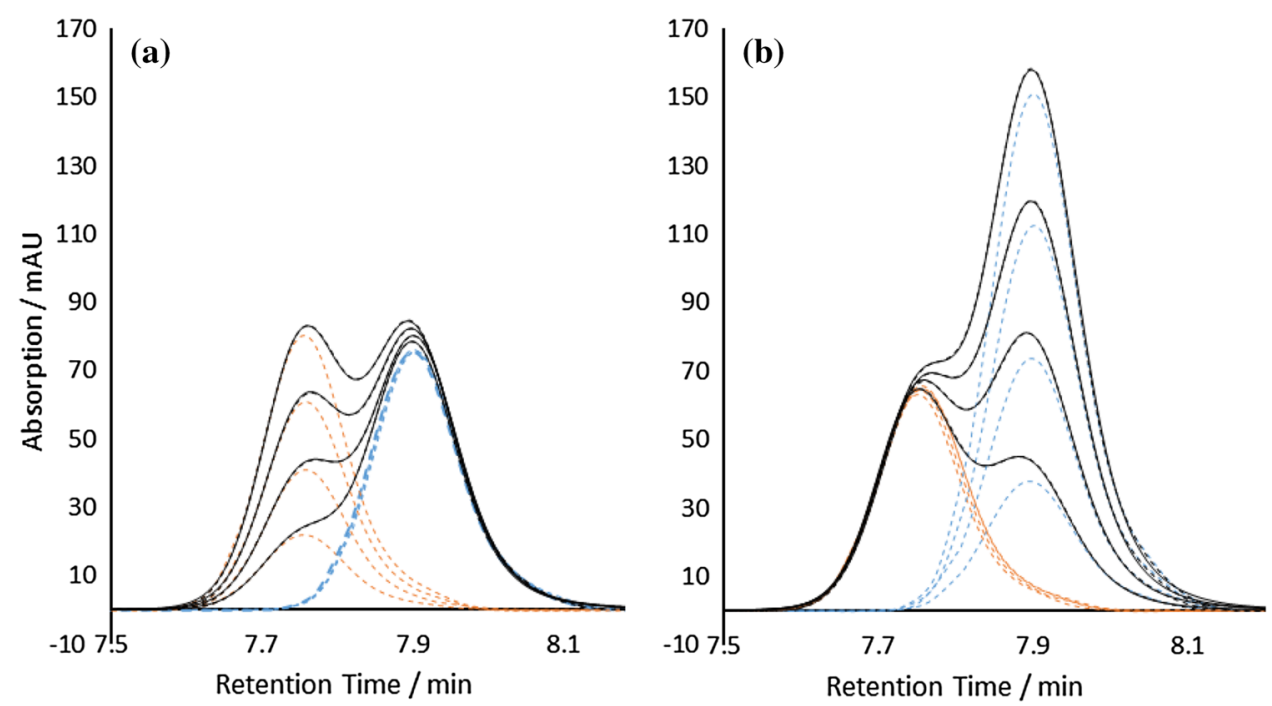
the relative peak interference observed for each complex is not equal. Figure 5a,b illustrates the two extremities: high [Co(III)-EDTA] and variable [Fe(III)-EDTA], and high [Fe(III)-EDTA] and variable [Co(III)-EDTA], recorded at 258 and $228 \mathrm{~nm}$, respectively. Proportionally, the peak overlap is greater for the Fe(III)-EDTA peak at $258 \mathrm{~nm}$, than for Co(III)-EDTA at $228 \mathrm{~nm}$. This effect is expressed by the greater standard error associated with the LSF of the Fe(III)-EDTA peaks.

In PARAFAC, the three-way data array from the HPLC-DAD is decomposed into three loading matrices. Mode 1 (Fig. 6a) shows the loadings with respect to chromatographic retention time. The two component peaks are clearly identifiable as $\mathrm{Fe}(\mathrm{III})$-EDTA and Co(III)-EDTA by comparison to the calibration data. The loadings of Mode 2 (Fig. 6b) show the deconvoluted UV-spectra of the two components. The peak shapes and relative peak maxima align with the UV-absorption profiles determined for reference spectra of each complex.

\section{Trench leachate}

Three trench leachate samples (GD10, GD12 and GD13) were spiked with EDTA at three concentrations. The HPLC chromatograms recorded for these samples $(258 \mathrm{~nm}$ detection wavelength) are depicted in Fig. 7. All chromatograms are the average of the six chromatograms recorded for each sample. Though peaks other than the Fe(III)-EDTA peak were observable, none were identifiable as Fe(III)-NTA or Fe(III)-DTPA. No peaks were observed to suggest that interfering metal complexes are formed from competing ions that would have a deleterious effect on the quantification of results.

The chromatograms of GD13 trench leachate samples (Fig. 7 c) exhibit a small peak at $\mathrm{t}_{\mathrm{r}} \approx 5.2 \mathrm{~min}$, which is only visible in chromatograms of samples that have been spiked with the ligand. A large and well-resolved peak is observed in all the chromatograms recorded for the GD12 trench leachate samples (Fig. $7 \mathrm{~b}, \mathrm{t}_{\mathrm{r}} \approx 5.1 \mathrm{~min}$ ). The UV $\lambda_{\max }$ of the associated species is $264 \mathrm{~nm}$; hence, the feature is prominent in the data recorded at $258 \mathrm{~nm}$. The peak is not caused by $\mathrm{Fe}$ (III)-NTA, Fe(III)-DTPA or Fe(III)EDTA but could represent another of the organic complexants known to occur in the repository [24].

The Fe(III)-EDTA chromatographic peak shape and position (Fig. $7, \mathrm{t}_{\mathrm{r}} \approx 7.8 \mathrm{~min}$ ) deviates from those observed in the chromatograms recorded for purely aqueous solutions (calibration and $\mathrm{Fe}(\mathrm{III}) / \mathrm{Co}$ (III)-EDTA mixtures). This is most likely attributable to the variable chemistries of the environmental matrix of the trench leachate samples. A chromatographic shift is observed in one of the EDTA-spiked trench leachate samples (GD12, Fig. 7b) to a shorter retention time $\left(\Delta \mathrm{t}_{\mathrm{r}} \approx 0.2 \mathrm{~min}\right)$. Extraction of The UV-absorption profiles at the chromatographic peak maxima $\left(\mathrm{t}_{\mathrm{r}} \approx 7.54 \mathrm{~min}(\mathrm{GD} 12)\right.$ and $\left.\operatorname{tr} \approx 7.76 \mathrm{~min}(\mathrm{GD} 10 / 13)\right)$ shows that both of the detected species exhibit similar shapes and identical local absorption maxima, confirming that both are $\mathrm{Fe}$ (III)-EDTA.

To varying extents, all three EDTA-spiked leachate samples produce $\mathrm{Fe}$ (III)-EDTA peaks with greater asymmetry (peak tailing, Fig. 7). This effect may be associated with co-elution of the Fe(III)-EDTA with chemically similar species; the matrix may affect the protonation state of the ligand before it was injected into the buffered mobile phase, its mode of complexation, or associated counter-ions. A portion of the area associated with the peak tail was removed during the LSF procedure by holding the expansion factors that determine the extent of the asymmetry of the GCAS peak constant to the factors determined in the analysis of the calibration data. Therefore, some of the EDTA that is
Fig. 6 Overlay of loadings determined by PARAFAC in Modes 1 (chromatographic) (a) and 2 (spectral) (b) and raw chromatographic and spectral data obtained from calibration samples
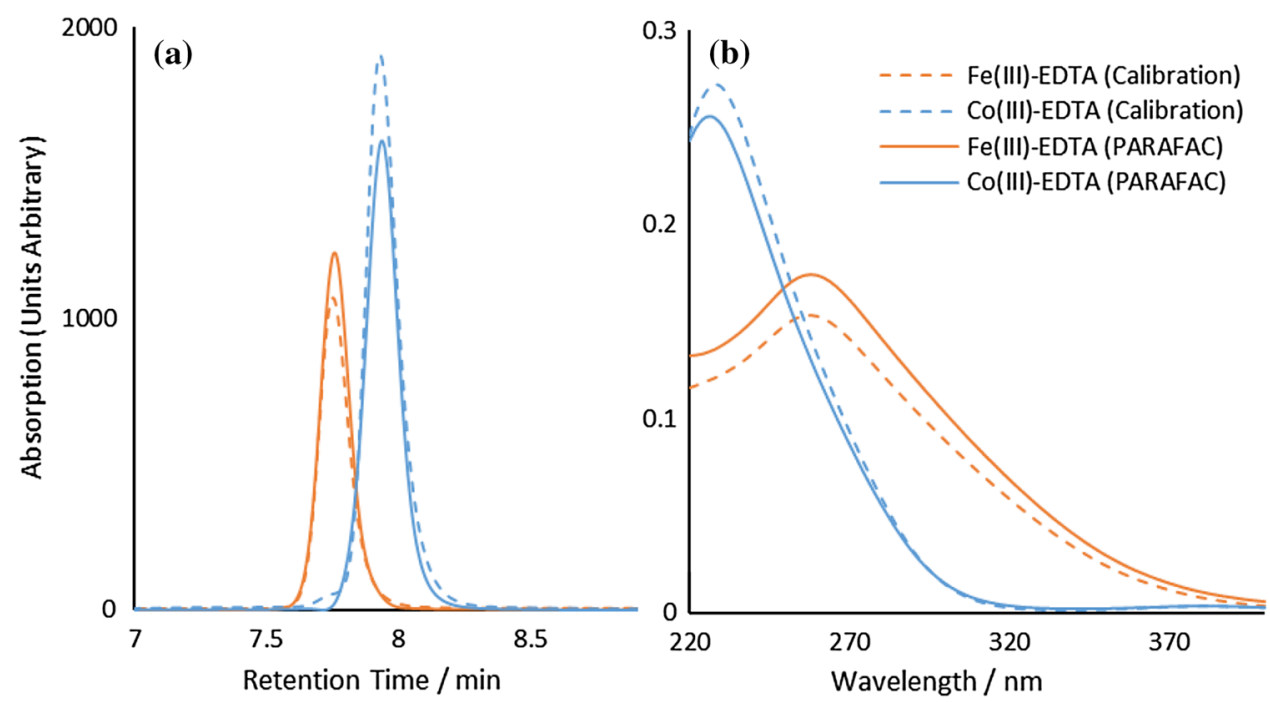

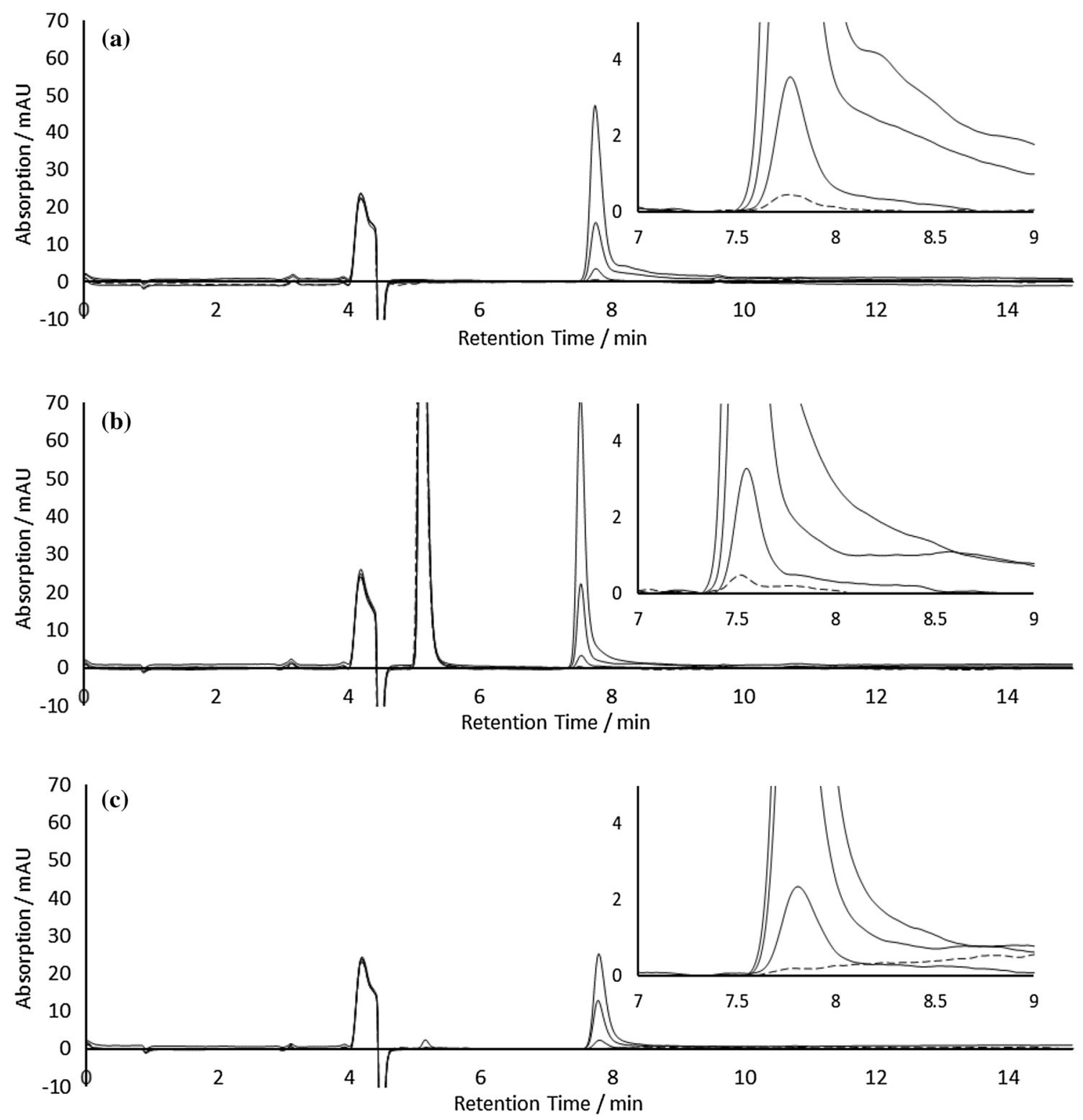

Fig. 7 Chromatograms recorded for trench leachate samples from GD10 (a), GD12 (b) and GD13 (c). Dashed lines represent the chromatograms for un-spiked samples, full lines represent the chromatograms for samples spiked with EDTA at various concentrations

not accounted for in the percent recovery as Fe(III)-EDTA is identifiable in the peak area that makes up the peak tails.

The spiked samples were analysed by HPLC before and after heating. The resulting chromatographic data was processed using the LSF procedure; LSF was found to be more reliable at low concentrations than PARAFAC (LSF/PARAFAC Fe(III)-EDTA LOD $=0.35 / 2.3 \mu \mathrm{M}$ ) and better suited for analysis of chromatograms with small variations in $t_{r}$. Table 5 shows the results as percent recovery.

The lowest values of percent recovery were observed for samples spiked with the highest concentration of EDTA $(782 \mu \mathrm{M})$. Here, the recovery of EDTA as Fe(III)-EDTA may have been limited by the quantity of $\mathrm{Fe}(\mathrm{IIII})$ available for complexation in the solution. Note that unbound EDTA does absorb in the UV-region of the spectrum $\left(\lambda_{\max }=270 \mathrm{~nm}\right.$ (disodium EDTA)) [43], but the absorption is weak and renders the uncomplexed ligand undetectable in the chromatograms. The mean concentration of Fe(III)-EDTA found in these samples was $61 \mu \mathrm{M}$; if $\mathrm{Fe}(\mathrm{III})$-complexation is assumed to be $100 \%$ in a roughly $1: 10$ excess of metal:ligand; this value gives an indication of the $\mathrm{Fe}$ (III) naturally present in the samples. We assume that the majority of the EDTA not recovered as $\mathrm{Fe}(\mathrm{III})$-EDTA remains uncomplexed in solution, noting that metal-EDTA complexes that do not absorb in the UV-region (190 - $400 \mathrm{~nm}$ ) would not have been detected and could feasibly account for a portion of 
Table 5 Concentration of $\mathrm{Fe}(\mathrm{III})$-EDTA detected in each trench leachate sample spiked with EDTA at three concentrations and the values of percent recovery of the spike (chromatographic peak area detected to expected peak area for spike concentration, expressed as percent)

\begin{tabular}{|c|c|c|c|c|c|c|c|c|c|c|}
\hline \multirow{2}{*}{ 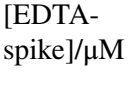 } & \multicolumn{2}{|l|}{ GD10 } & \multicolumn{2}{|l|}{ GD12 } & \multicolumn{2}{|l|}{ GD13 } & \multicolumn{2}{|l|}{ Average } & \multicolumn{2}{|l|}{$\sigma$} \\
\hline & No heat & Heat & No heat & Heat & No heat & Heat & No heat & Heat & No heat & Heat \\
\hline \multicolumn{11}{|c|}{$[\mathrm{Fe}(\mathrm{III})-\mathrm{EDTA}($ detected $)] / \mu \mathrm{M}$} \\
\hline 782 & 47 & 70 & 48 & 74 & 33 & 39 & 43 & 61 & 8.2 & 19 \\
\hline 78.2 & 18 & 26 & 20 & 23 & 18 & 19 & 19 & 22 & 1.2 & 3.4 \\
\hline 7.82 & 3.6 & 5.1 & 4.2 & 3.9 & 3.9 & 3.9 & 3.9 & 4.3 & 0.3 & 0.7 \\
\hline \multicolumn{11}{|c|}{ Percent recovery of EDTA-spike as $\mathrm{Fe}(I I I)$-EDTA/\% } \\
\hline 782 & 5.9 & 8.9 & 6.2 & 9.5 & 4.3 & 4.9 & 5.5 & 7.8 & 1.0 & 2.5 \\
\hline 78.2 & 23 & 33 & 26 & 29 & 23 & 24 & 24 & 29 & 1.6 & 4.3 \\
\hline 7.82 & 46 & 65 & 54 & 50 & 50 & 50 & 50 & 55 & 4.1 & 9.0 \\
\hline
\end{tabular}

Data recorded before and after the spiked solutions were heated for $12 \mathrm{~h}$ at $65^{\circ} \mathrm{C}$ the EDTA not recovered as Fe(III)-EDTA. The lowest mean recovery for the samples spiked with $78.2 \mu \mathrm{M}$ of EDTA was $24 \%$. The recovery is still relatively low despite there being a roughly 1:1 molar equivalence of metal:ligand present in solution, assuming $61 \mu \mathrm{M}$ is a reasonable approximation of the Fe(III) available for complexation. Other matrix effects may contribute to the low recovery, for example, the $\mathrm{pH} / \mathrm{Eh}$ environment or competing ions.

Figure 8a shows that the recovery increases logarithmically with decreasing concentration of EDTA and that heating the samples at $65^{\circ} \mathrm{C}$ for $12 \mathrm{~h}$ only marginally increases the recovery. The percent recovery of the EDTA-spike as Fe(III)-EDTA (Fig. 8b) can be used to calculate the total EDTA in un-spiked trench leachate solutions, given the respective concentrations of $\mathrm{Fe}$ (III)-EDTA detected in each sample (i.e. substituting $x$ for the detected Fe(III)EDTA concentration into the linear equation for Fig. 8b, $y=-17.51 \ln (\mathrm{x})+80.97$ and solving for $y$, then dividing the
$\mathrm{Fe}$ (III)-EDTA detected by $y$ to obtain the total concentration of EDTA). The results are presented in Table 6.

$\mathrm{Fe}(\mathrm{III})$-EDTA was detected in four out of the six samples of trench leachate tested. All of the concentrations determined from the peak area obtained by LSF of the chromatographic data fall between the LOD and the LOQ. The concentrations reported here are similar to those obtained in a previously reported analysis [44]. This and that study both suggest that the EDTA loading in trench leachate from the sampling locations tested does not exceed $1 \mu \mathrm{M}$.

\section{Conclusion}

Optimising the method originally outlined by Nowack et al., a robust and sensitive RP-HPLC procedure has been developed to detect three common APCAs at trace concentrations in complex aqueous matrices. The sensitivity of
Fig. 8 a Plot of the $\log _{10}$ of spiked concentration of EDTA against the mean percent recovery as Fe(III)-EDTA from the trench leachate samples before (blue) and after (orange) heating, $\mathbf{b}$ plot of the $\log _{10}$ of Fe(III)-EDTA concentration detected as a function of the mean percent recovery of spiked EDTA after heating. The result of linear regression the plot is indicated and used for calculating total amounts of EDTA in un-spiked trench leachate samples. See text for details

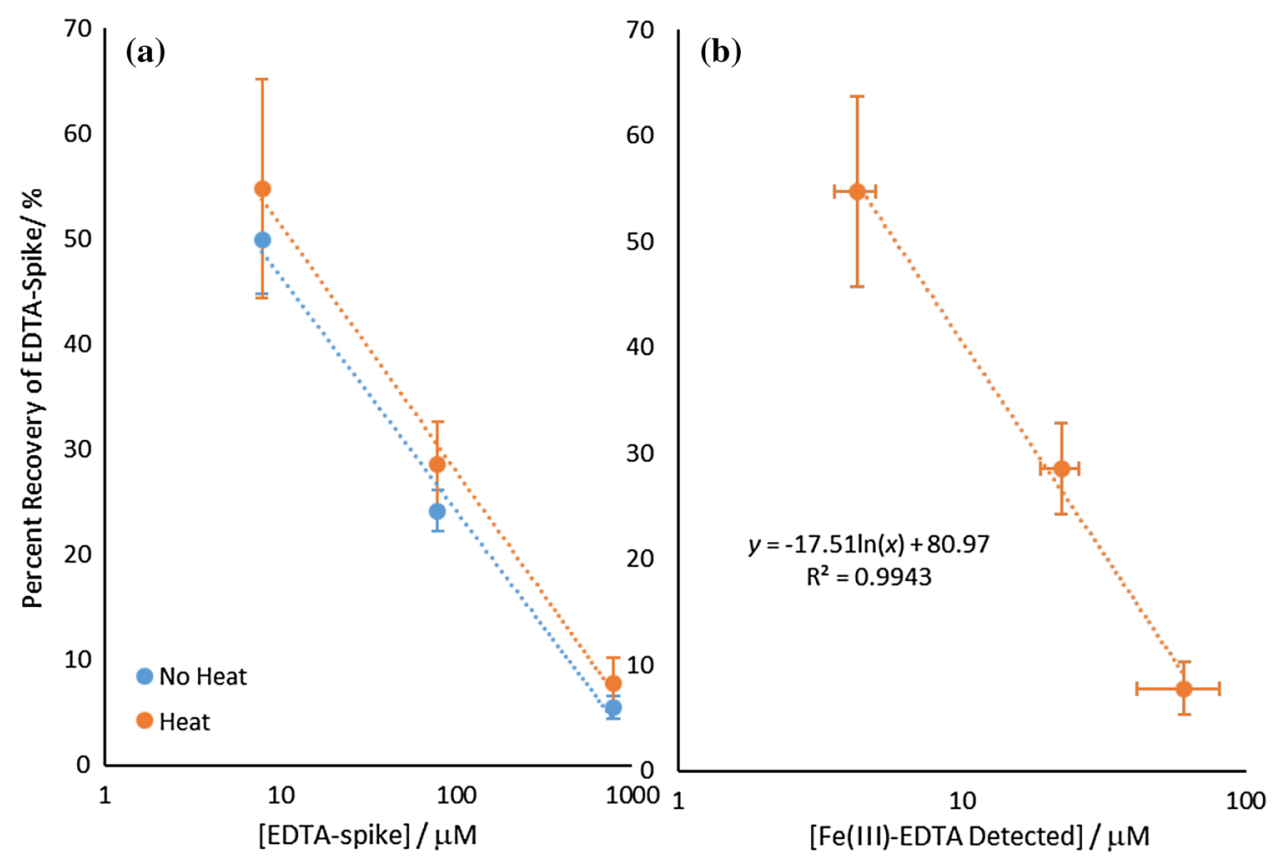


Table 6 Concentrations of Fe(III)-EDTA detected in un-spiked samples of trench leachate from various sampling locations, the fraction of the total EDTA (as a percentage) determined by extrapolation of the trend in Fig. 8b, and the calculated total concentration of EDTA in each sample

\begin{tabular}{llll}
\hline Trench leachate sample & {$[\mathrm{Fe}(\mathrm{III})-\mathrm{EDTA}] / \mu \mathrm{M}$} & Fraction of Total EDTA/ \% & {$[\mathrm{EDTA}] / \mu \mathrm{M}$} \\
\hline GD6 & 0.7 & 87 & 0.8 \\
GD7 & 0.4 & 99 & 0.4 \\
GD8 & $\mathrm{ND}$ & $\mathrm{ND}$ & $\mathrm{ND}$ \\
GD10 & 0.5 & 92 & 0.6 \\
GD12 & 0.4 & 98 & 0.4 \\
GD13 & $\mathrm{ND}$ & $\mathrm{ND}$ & $\mathrm{ND}$ \\
\hline
\end{tabular}

$N D$ not detected

our method for EDTA and DTPA was found to be suitably high for application to LLWR leachate samples.

The monolithic stationary phase used in this analysis was found to afford greater peak resolution than a conventional particle-based $\mathrm{C}_{18}$ column (SI). The monolithic silica was also proven to be robust (inter-day $\% \mathrm{RSD}<10 \%$ ), which has economical value as it helps to offset the greater investment associated with the polymeric stationary phase.

Method validation has demonstrated the HPLC method to be linear $\left(r^{2}>0.98\right)$, precise (intra/inter-day $\%$ RSD $\leq 10 \%)$ and selective. Full conversion of EDTA to $\mathrm{Fe}(\mathrm{III})$-EDTA was observed in a sample matrix containing only $\mathrm{H}_{2} \mathrm{O}$ (recovery $=100 \pm 5 \%$ ); however, the experimental results of the EDTA-spiked samples of trench leachate suggest that the recovery is, of course, limited by the amount of $\mathrm{Fe}$ (III) in solution available for binding but also decreases significantly when subject to matrix effects (recovery of $7.82 \mathrm{mM}$ EDTA-spike $=55 \pm 9 \%$ ). Addition of $\mathrm{Fe}$ (III) to amounts well above the unknown EDTA concentration of an analyte solution can adversely impact the $\mathrm{UV}-\mathrm{Vis}$ detection in the procedure. To account for the decreased recovery due to matrix effects, the recovery of EDTA spiked to a series of leachate samples was used to determine a logarithmic trend between concentration and recovery, which in turn was used to introduce a correction factor in the analysis of un-spiked samples. Without this correction factor for low EDTA concentrations in the samples studied, the result underestimates the amount of EDTA by around $15 \%$.

To guard against the potential complications introduced to the procedure by competing ions or other interfering species, two peak deconvolution methods have been successfully applied to HPLC-DAD data recorded for various mixtures of Fe(III)- and Co(III)-EDTA. The accuracy of each method was comparable; most data points fell within the range $100 \pm 10 \%$ (deconvoluted peak area as a percentage of calibration sample peak area). Neither deconvolution method was able to accurately quantify the low intensity peak in mixtures where the concentration disparity was two orders of magnitude $(1000 / 10 \mu \mathrm{M})$. The LSF procedure was found to be more reliable at low concentrations (LSF/PARAFAC Fe(III)-EDTA LOD $=0.35 / 2.3 \mu \mathrm{M}$ ), hence, it was used in the analysis of trench leachate samples from LLWR.

Each deconvolution method has pros and cons. For example, there is a significant time penalty associated with the LSF procedure, though this could be reduced by introducing a coded routine to perform the task automatically. The PARAFAC model could process the data much faster, but the software is not a black-box; some amount of time and understanding is required to get a reasonable output. In the future, the PARAFAC model could be improved by introducing PARAFAC2 code, which is more flexible than PARAFAC, allowing for certain shifts in one of the modes (e.g. could account for chromatographic retention time drift) [45].

Of the six trench leachate samples that were tested, four were found to contain trace concentrations of EDTA, all of which fall below the LOQ $(1 \mu \mathrm{M})$. The total concentration of $\mathrm{Fe}(\mathrm{III})$-EDTA found in the trench leachate samples ranges from 0.4 to $0.7 \mu \mathrm{M}$, which translates to an EDTA concentration range of $0.4-0.8 \mu \mathrm{M}$, should the correction calculation by extrapolation of recoveries of spiked samples be taken into account. The levels are not considered sufficient to increase the risk of radionuclide mobilisation. The technique is considered to be robust and will be considered further in informing limits of acceptance on APCAs.

Acknowledgements This work was supported by The Low Level Waste Repository Ltd and The Engineering and Physical Sciences Research council.

Open Access This article is distributed under the terms of the Creative Commons Attribution 4.0 International License (http://creativeco mmons.org/licenses/by/4.0/), which permits unrestricted use, distribution, and reproduction in any medium, provided you give appropriate credit to the original author(s) and the source, provide a link to the Creative Commons license, and indicate if changes were made. 


\section{References}

1. LLWR (2011) Environmental safety case-main report, LLWR/ ESC/R(11)10016. LLWR, Cumbria

2. Rufus AL, Velmurugan S, Sathyaseelan VS, Narasimhan SV (2004) Comparative study of nitrile triacetic acid (NTA) and EDTA as formulation constituents for the chemical decontamination of primary coolant systems of nuclear power plants. Prog Energ Nucl. https://doi.org/10.1016/S0149-1970(04)90005-4

3. Butcheli-Witschel M, Elgi T (2001) Environmental fate and microbial degradation of aminopolycarboxylic acids. FEMS Microbiol Rev 25:69-106. https://doi.org/10.1111/j.1574-6976.2001.tb005 72.x

4. Means JL, Alexander CA (1981) The environmental biogeochemistry of chelating agents and recommendations for the disposal of chelated radioactive wastes. Nucl Chem Waste Manag 2:183-193. https://doi.org/10.1016/0191-815X(81)90014-0

5. Radioactive waste management (2016) geological disposal behaviour of radionuclides and non-radiological species in groundwater status report, NDA Report No. DSSC/456/01. RWM, Oxford, UK

6. Norwegian Radiation Protection Authority (2018) Study of issues affecting the assessment of impacts of disposal of radioactive and hazardous waste, NRPA Report 2018:6. Østerås, Statens Strålevern, Norway

7. Serne RJ, Cantrell KJ, Lindenmeier CW, Owen AT, Kutnyakov IV, Orr RD, Felmy AR (2002) Radionuclide-chelating agent complexes in low-level radioactive decontamination waste; stability, adsorbtion and transport potential, NUREG/CR- 6758 PNNL- 13774. U.S. Nuclear Regulatory Commission, Washington D.C., USA

8. Smillie S, Glasser FP (1999) Reactions of EDTA, oxalic acid and citric acid with Portland cement. Adv Cem Res 11:97-101. https://doi.org/10.1680/adcr.1999.11.2.97

9. LLWR (2012) Waste acceptance criteria-supercompactable waste, WSC-WAC-SUP-V3.0. LLWR, Cumbria, UK

10. LLWR (2013) Developments Since the 2011 ESC, LLWR/ ESC/R(13)1005 Issue 1. LLWR, Cumbria

11. Agency Environment (2015) Review of LLW Repository Ltd's 2011 Environmental Safety Case: Inventory and Near Field, Issue 1. Environment Agency, Bristol

12. LLWR (2016) Waste acceptance criteria-low level waste disposal, WSC-WAC-LOW-V5.0. LLWR, Cumbria, UK

13. Kelly M (2013) Preliminary calculations to assess the impact of EDTA on health hazards arising from the LLWR, Report AMEC/006357/002. AMEC, Cumbria, UK

14. Health and Safety Executive (2004) Rosyth Royal Dockyard Ltd's stategy for decommissioning the Rosyth Nuclear Licenced Site. HSE, Merseyside

15. Sillanpää M (1997) In: Ware G W (ed) Reviews of Environmental Contamination and Toxicology. Springer, New York, https:// doi.org/10.1007/978-1-4612-1964-4_3

16. Laine P, Matilainen R (2005) Simultaneous determination of DTPA, EDTA and NTA by UV-visible spectrometry and HPLC. Anal Chem Bioanal. https://doi.org/10.1007/s00216-005-3315-0

17. Sýkora V, Pitter P, Bittnerová I, Lederer T (2001) Biodegradability of ethylenediamie-based complexing agents. Water Res. https://doi.org/10.1016/S0043-1354(00)00455-3

18. Nowack B, Kari FG, Hilger SU, Sigg L (1996) Determination of dissolved and adsorbed EDTA species in water and sediments by HPLC. Anal Chem. https://doi.org/10.1021/ac9507505

19. Means JL, Kucak T, Crerar DA (1980) Relative degradation rates of NTA EDTA and DTPA and environmental implications. Environ Pollut. https://doi.org/10.1016/0143-148X(80)90020-8
20. Svenson A, Kaj L, Björndal H (1989) Aqueous photolysis of iron (III) complexes of NTA, EDTA and DTPA. Chemosphere 18:1805-1808. https://doi.org/10.1016/0045-6535(89)90464-5

21. Toste AP (1992) Degradation of chelating and complexing agents in an irradiated simulated mixed waste. J Radioanal Nucl Chem. https://doi.org/10.1007/BF02040502

22. Toste AP, Osborn BC, Polach KJ, Lechner-Fish TJ (1995) Organic analyses of an actual and simulated mixed waste: Hanford's organic complexant waste revisited. J Radioanal Nucl Chem. https://doi.org/10.1007/BF02037609

23. Tian K, Benson CH, Tinjum JM (2017) Chemical characteristics of leachate in low-level radioactive waste disposal facilities. J Hazard Toxic Radioact. Waste. https://doi.org/10.1061/(ASCE) HZ.2153-5515.0000361

24. LLWR (2013) Review of the Potential Effects of Complexants on Contaminant Transport at the LLWR, LLWR/ESC/R(13)10054. LLWR, Cumbria

25. Randt C, Wittlinger R, Merz W (1993) Analysis of nitrilotriacetic acid (NTA), ethylenediaminetetraacetic acid (EDTA) and diethylenetriaminepentaacetic acid (DTPA) in water, particularly waste water Frensius. J Anal Chem. https://doi.org/10.1007/BF003 21281

26. Taddia M, Lippolis MT, Pastorelli L (1979) Potentiometric determination of EDTA and NTA in detergents. Microchem. J 24(1):102-106. https://doi.org/10.1016/0026-265x(79)90045-6

27. Bürgisser CS, Stone AT (1997) Determination of EDTA, NTA and other amino carboxylic acids and their $\mathrm{Co}(\mathrm{II})$ and $\mathrm{Co}(\mathrm{III})$ complexes by capillary electrophoresis. Environ Sci Technol 31(9):2656-2664. https://doi.org/10.1021/es970080f

28. Sillanpää M, Sihvonen M-L (1997) Analysis of EDTA and DTPA. Talanta. https://doi.org/10.1016/S0039-9140(97)00059-3

29. Kemmeia T, Kodamaa S, Yamamotob A, Inouec Y, Hayakawad K (2013) Determination of ethylenediaminetetraacetic acids in foods by reversed-phase high-performance liquid chromatography. Food Chem. https://doi.org/10.1016/j.foodchem.2012.11.103

30. De Jong J, Van Polanen A, Driessen JJM (1991) Determination of ethylenediaminetetraacetic acid and its salts in canned mushrooms by reversed-phase ion-pair liquid chromatography. J Chromatogr A. https://doi.org/10.1016/S0021-9673(01)88494-6

31. Wang G, Tomasella FP (2016) Ion-pairing HPLC methods to determine EDTA and DTPA in small molecule and biological pharmaceutical formulations. J Pharm Anal. https://doi. org/10.1016/j.jpha.2016.01.002

32. Geschke R, Zehringer M (1997) A new method for the determination of complexing agents in river waters using HPLC Frensius. J Anal Chem. https://doi.org/10.1007/s002160050247

33. Ali I, Gaitonde VD, Aboul-Enein HY (2009) Monolithic silica stationary phases in liquid chromatography. J Chromatogr Sci. https://doi.org/10.1093/chromsci/47.6.432

34. Smith RM, Martell AE (1989) Critical Stability Constants, 6th edn. Plenum Press, New York

35. Bro R (1997) PARAFAC. Tutorial and applications. Chemom Intell Lab Syst. https://doi.org/10.1016/S0169-7439(97)00032-4

36. Harshman RA (1970) Foundations of the PARAFAC procedure: models and conditions for an "explanatory" multimodal factor analysis UCLA Working Papers in Phonetics 16:1-84

37. Carroll JD, Chang J-J (1970) Analysis of individual differences in multidimensional scaling via an n-way generalization of "EckartYoung" decomposition. Psychometrika. https://doi.org/10.1007/ bf02310791

38. Guizellini FC, Marcheafave GG, Rakocevic M, Bruns RE, Scarminio IS, Soares PK (2018) PARAFAC HPLC-DAD metabolomic fingerprint investigation of reference and crossed coffees. Food Res Int. https://doi.org/10.1016/j.foodres.2018.06.070

39. Soares PK, Marcheafave GG, Gomes AA, Scarminio IS, Bruns RE (2018) Mixture design PARAFAC HPLC-DAD metabolomic 
fingerprints of fractionated organic and basic extracts from erythrina speciosa andrews leaves. Chromatographia. https://doi. org/10.1007/s10337-018-3554-9

40. Dondi F, Betti A, Bio G, Bighi C (1981) Statistical analysis of gas chromatographic peaks by the Gram-Charlier series of type A and the Edgeworth-Cramér series. Anal Chem. https://doi. org/10.1021/ac00226a026

41. Grushka E (1972) Chromatographic peak shapes. Their origin and dependence on the experimental parameters. J Phys Chem. https ://doi.org/10.1021/j100662a020

42. Miller JN, Miller JC (2010) Statistics and chemometrics for analytical chemistry, 6th edn. Pearson, Harlow
43. Kamboj S, Sharma D, Nair AB, Kamboj S, Sharma RK, Ali J, Pramod K, Ansari SH (2011) Simple spectrophotometric method for estimation of disodium edetate in topical gel formulations. Pharm Methods. https://doi.org/10.4103/2229-4708.84448

44. Enviras, Results of the measurement of the concentration of dissolved EDTA in trench waters from LLWR by HPLC, unpublished work

45. Jørgensen P J H, Nielsen S F V, Hinrich J L, Schmidt M N, Madsen K H, Mørup M (2018) Probabilistic PARAFAC2, arXiv :1806.08195 [stat.ML]

Publisher's Note Springer Nature remains neutral with regard to jurisdictional claims in published maps and institutional affiliations. 